University of Nebraska - Lincoln

DigitalCommons@University of Nebraska - Lincoln

Sociology Department, Faculty Publications

Sociology, Department of

2010

An Examination of Questionnaire Evaluation by Expert Reviewers

Kristen Olson

University of Nebraska-Lincoln, kolson5@unl.edu

Follow this and additional works at: https://digitalcommons.unl.edu/sociologyfacpub

Part of the Sociology Commons

Olson, Kristen, "An Examination of Questionnaire Evaluation by Expert Reviewers" (2010). Sociology Department, Faculty Publications. 136.

https://digitalcommons.unl.edu/sociologyfacpub/136

This Article is brought to you for free and open access by the Sociology, Department of at DigitalCommons@University of Nebraska - Lincoln. It has been accepted for inclusion in Sociology Department, Faculty Publications by an authorized administrator of DigitalCommons@University of Nebraska - Lincoln. 


\title{
An Examination of Questionnaire Evaluation by Expert Reviewers
}

\author{
Kristen Olson \\ Department of Sociology and Survey Research and Methodology Program, \\ University of Nebraska-Lincoln, PO Box 880324, Lincoln, NE 68588, USA; \\ email kolson5@unl.edu
}

\begin{abstract}
Expert reviews are frequently used as a questionnaire evaluation method but have received little empirical attention. Questions from two surveys are evaluated by six expert reviewers using a standardized evaluation form. Each of the questions has validation data available from records. Large inconsistencies in ratings across the six experts are found. Despite the lack of reliability, the average expert ratings successfully identify questions that had higher item nonresponse rates and higher levels of inaccurate reporting. This article provides empirical evidence that experts are able to discern questions that manifest data quality problems, even if individual experts vary in what they rate as being problematic. Compared to a publicly available computerized question evaluation tool, ratings by the human experts positively predict questions with data quality problems, whereas the computerized tool varies in success in identifying these questions. These results indicate that expert reviews have value in identifying question problems that result in lower survey data quality.
\end{abstract}

Keywords: questionnaire design, pretesting, measurement error, expert reviewers 


\section{Introduction}

Survey researchers frequently ask a team of experts to review questionnaires as a method of identifying question problems, breakdowns in the question-answering process, and other potential measurement errors in survey reports. In an expert review, survey methodologists, psychologists, sociologists, or other people familiar with questionnaire design identify potential problems with a survey questionnaire. Although many varieties of expert reviews exist (Willis et al. 1999), two primary goals of an expert review are to reveal problems with a survey instrument so that they can be remedied prior to going into the field or to sort items into groups that are more or less likely to exhibit measurement errors. For example, expert reviewers have been used as a pretesting method (Presser and Blair 1994; Esposito and Rothgeb 1997; Willis et al. 1999), to identify problematic linguistic structures in survey questions (Holbrook et al. 2007), and for classification of items related to interviewer effects (Mangione et al. 1992; Schnell and Kreuter 2005). The number of expert reviewers tends to be small, ranging from two or three expert methodologists (Presser and Blair 1994; Theis et al. 2002; Jansen and Hak 2005; Holbrook et al. 2007) to over 20 reviewers (Willis et al. 1999). In general, expert review is a relatively quick and inexpensive method for evaluating questionnaires (Presser and Blair 1994). Although this method is easy to implement, whether different experts reliably identify the same problems in a questionnaire has received relatively little attention. In addition, the ability of experts to discern questions that are prone to item nonresponse or inaccurate reports has not been examined. This article addresses both of these issues.

Most examinations of expert review compare this method to other pretesting methods such as behavior coding and cognitive interviews (Presser and Blair 1994; Rothgeb et al. 2001; Jansen and Hak 2005; Graesser et al. 2006). Despite the widespread use of this technique, few empirical evaluations exist of the expert review method itself. In particular, there is little evidence as to whether different expert reviewers identify similar question problems (Tourangeau 2004). After a search of the peer-reviewed literature and conference proceedings, only three studies were identified that explicitly look at variation across experts, two examining one expert from each of the three organizations (Rothgeb et al. 2001; DeMaio and Landreth 2003) or differences across two panels of experts (Presser and Blair 1994). These studies found disagreement about problems with individual questions across the experts, but differences across experts and differences across organizations cannot be easily disentangled. 
DeMaio and Landreth (2003) suggest four reasons why experts might differ in the number and types of problems that they identify on survey questions. These include the time each expert spent on the task, their expectations about the task, their perceptions about what makes "good" or "bad" questions, their experience or training in conducting evaluations of questionnaires, and whether the review is conducted collaboratively or individually. Other reasons for disagreement across experts are related to the degree of standardization in the task, such as whether explicit forms or codes are used for the evaluation (Willis et al. 1999), the degree to which the expert is familiar with the subject matter content of the questionnaire (Ramirez 2002), and the amount of context given to the experts about the questionnaire administration (Ramirez 2002). This would suggest that some variation in expert ratings can be controlled by standardizing the task given to the expert, much like standardizing the interviewer's task (Cannell et al. 1981), but that other variation cannot be easily controlled without specific selection of experts (e.g., that related to experience or background knowledge).

Implicitly assumed by the use of expert review is that the questions that are identified as being "problematic" by the experts actually yield higher levels of measurement error than other questions (Tourangeau 2004). Evaluations of the quality of expert reviews compare it to other methods containing proxy indicators of data quality, such as interviewer and respondent behaviors during an interview (Presser and Blair 1994; Forsyth et al. 2004; Schaeffer and Dykema 2004). These comparisons show that experts identify more problems than other methods and that there is often little overlap between the methods. To identify whether the problems identified by experts actually are associated with inaccurate survey reports, a record base containing a "gold standard" for the responses must be available for this comparison, unavailable for many questions or populations.

This article addresses these two gaps in the research literature. Variation across experts in their reviews of question problems is examined, as is whether questions identified as problematic by the experts are systematically related to data quality problems -item nonresponse and report inaccuracy - on those questions. Two surveys are used, selected because of their record bases for items that were also asked in the questionnaire. Human experts are compared to an "expert" computer system designed to identify potential question comprehension problems (Graesser et al. 2006), the response process most frequently identified as potentially failing in expert reviews (DeMaio and Landreth 2003). Thus, this article aims to answer two questions: Are expert reviewers consistent in identifying 
problematic questions? Do expert reviews adequately identify questions that result in data quality problems?

\section{Data and Method}

Questions from two surveys were reviewed. All questions reported here were selected because of the availability of validation data from records. As such, all selected questions are behavioral or other questions about autobiographical events; attitudinal questions are excluded because of the lack of validation data. The types of questions range from dates to dollar amounts (questions that respondents frequently have difficulty answering precisely; see, e.g., Tourangeau et al. 2000) to the presence or absence of important life events (questions that are often answered more accurately). Most of the questions are open ended.

\section{Description of the Surveys}

\section{The Wisconsin Divorce Study}

The 1995 Wisconsin Divorce Study (WDS) selected a random sample from divorce certificates from four counties in Wisconsin from 1989 to 1993. Sampled persons in the WDS were asked to participate in the Life Events and Satisfaction Survey, a mixed mode study starting with a telephone request with nonrespondents followed up by mail. Overall, approximately 730 persons were attempted, and the response rate (AAPOR RR2, American Association for Public Opinion Research [AAPOR] 2006) was $71 \%$, with a contact rate of $80 \%$ and a cooperation rate of $88 \%$.

The survey contained questions on satisfaction with life and relationships, marital and cohabitation history, childbearing history, education and work history, satisfaction with current relationships, and demographics. The divorce certificates contain demographics for both members of the divorcing couples (gender, race, and education level) and information about child custody arrangements that result from the divorce as well as divorce, marriage, and birth dates and the number of marriages. In total, the experts examined and rated 31 questions in this survey, including the questions immediately preceding and following the questions reported here. I focus on six questions from this survey, including the month and date of birth, marriage, and divorce, whether the individual had ever been married, divorced, and the number of previous marriages. 


\section{National Postsecondary Student Aid Study (NPSAS)}

The U.S. National Center for Education Statistics sponsored the 2004 NPSAS. The NPSAS was also a mixed mode survey, in which sampled students in the NPSAS were recruited by e-mail and a personalized advance letter to participate in a Web survey, followed up with telephone requests. Details about the sample design and methodology for the NPSAS are described in detail elsewhere (Cominole et al. 2006). This article focuses on the experts' ability to discern the accuracy of reports among questions answered by undergraduates, an analytic data set of over 68,000 students. Data quality estimates account for the complex survey design and unequal weights. The contact rate for this set of undergraduates was high - 96\% (AAPOR weighted CON2) - and the cooperation rate is $73 \%$, with an overall response rate of $70 \%$ (AAPOR weighted RR2; see AAPOR 2006).

The survey contained questions about sources and amount of financial aid, school attendance, academic major, academic performance, and demographics. The record data contained financial aid information obtained from the school or university and from two federal databases on student loans and grants - the Free Application for Federal Student Aid (FAFSA) and the National Student Loan Data System. The records also include measures of academic performance. The experts rated 78 questions in this survey, presented in the order in which they appeared in the questionnaire. The 11 questions of interest for this analysis include whether the student applied for and received financial aid, particular types and amounts of aid, and grade point average.

\section{Data Quality Indicators}

I look at two data quality measures -item nonresponse and inaccuracy rates. Item nonresponse is selected because it is the data quality measure most likely to be available to other survey analysts. Response inaccuracy uses the records available for each survey and examines whether the survey reports exactly match those in the records. For date questions, accuracy is measured to the month and year reported. For grade point average, accuracy is measured to the second decimal, the level of detail asked for in the questionnaire.

Item nonresponse rates in both surveys are quite low. In the WDS, they range from no item nonresponse on a question of ever being married to under $9 \%$ for the divorce date. In the NPSAS, item nonresponse rates on these questions are no more than $4 \%$. In contrast, both surveys 
have questions with large amounts of inaccurate reporting. For example, up to half of the divorce dates are misreported (to the month and year) in the WDS and almost $83 \%$ of the grade point average (GPAs) is misreported in the NPSAS (to the second decimal). For other WDS items, inaccurate reports range from 1.5\% (ever being married) to about 33\% (marriage date). Inaccuracy rates on other items in the NPSAS range from about 7\% (receiving Pell Grants or Work Study aid) to just under 25\% (amounts of state and institutional aid). Despite the large proportions of inaccurate reports, the magnitude of the misreports is small. For example, reports of divorce dates are, on average, only about 6 months off of the actual date and the average magnitude of the difference in reported grade point average is less than 0.2 points. So that a common metric can be examined on all items, I use a binary measure of accurate versus inaccurate reports.

\section{Description of the Expert Reviews}

Six expert reviewers - the author plus five additional reviewersparticipated in this study. Five of the expert reviewers were employed at the same academic survey research organization; one was employed at a different large-scale survey research organization. The reviewers were selected because they had similar background training of at least a master's degree in survey methodology, psychology, or related fields. All of the reviewers had taken graduate-level coursework related to questionnaire design and/ or the social and cognitive processes of survey measurement and/or had at least 2 years of prior work experience in survey organizations. Thus, the experts were selected to minimize variation in background characteristics across the experts, rather than attempting to draw a probability sample of all experts. The experts conducted their review independently. To maintain independence of the reviews, all reviewers were asked to conduct the reviews individually; the identity of the other reviewers was not revealed to any reviewer aside from the author. Additionally, all ratings (other than the author's) were conducted without knowledge of the empirical measurement error properties of the reports.

A new question evaluation tool was developed for this research, based off existing appraisal tools (Presser and Blair 1994; Willis et al. 1999; Rothgeb et al. 2001; Theis et al. 2002; Graesser et al. 2006) and the cognitive response process (Tourangeau 1984; Tourangeau et al. 2000). For each question, the reviewers were asked to rate both cognitive and motivational characteristics of questions (Jansen and Hak 2005). Reviewers 
first rated motivational characteristics of the question, including whether the question or characteristic measured by the question was burdensome (requires a great deal of cognitive work by the respondent), sensitive (requires revealing embarrassing or private information or the topic is not discussed in everyday conversation), or socially undesirable (requires revealing information that may be compared against a social norm for possessing or not possessing a characteristic). Reviewers then rated whether they thought any failure of any part of the cognitive response process was likely to occur on that question.

For those questions rated as possibly experiencing failures, each expert rated the likelihood of the breakdown occurring at each stage of the cognitive response process on a 4-point scale ranging from not at all likely to very likely that a failure of this stage will occur. The four stages are comprehension (understanding the question), retrieval (obtaining the information for the question from memory), judgment (evaluating the retrieved information and whether it meets the question objectives), and editing (modifying the response; Tourangeau et al. 2000). The experts also were asked to provide written comments with more detailed information about the individual types of problems they thought were likely to occur.

All experts examined the same questions using forms developed by the author (see Appendix). In the WDS, the 6 questions examined here result in a total of 36 expert ratings. In the NPSAS, the 10 questions examined here yield a total of 60 expert ratings.

As a comparison, each question was also evaluated by the Question Understanding Aid (QUAID), a publicly available Web application designed to identify wording problems in survey questions (Graesser et al. 2006). This comparison allows me to discern whether any given expert system, human or computer, performs better in identifying problematic questions. The use of the QUAID tool also provides a comparison between the somewhat broader categories evaluated by the experts and the more detailed wording problems identified by the QUAID tool. Each question and response options (where applicable) was entered into QUAID. The number of problems QUAID identified was counted, ranging from zero to five for the questions here. Each identified vague or unfamiliar word was counted individually; this was the most common critique of the problematic questions. If both expert systems are identifying similar problems, I would expect positive associations between the human experts and QUAID. QUAID identifies problems with syntactical structure of questions, so I expect the strongest association between the expert ratings and the QUAID ratings to be for comprehension difficulties. 


\section{Analysis}

The analysis proceeds in three steps. First, I look at agreement across the experts. There are many measures for examining agreement across raters, differing in whether the measure accounts for agreements occurring by chance, whether the ratings are assumed to be nominal or ordinal, and whether items and raters are assumed to be fixed or randomly selected (Schrout and Fleiss 1979; Banerjee et al. 1999). As such, three measures were used to indicate the degree of agreement across the reviewers in their ratings - the proportion of all two-way combinations of reviewers who provide exactly the same rating across all of the questions (the match rate), a multiple coder kappa (Kalton and Stowell 1979), and an intraclass correlation coefficient (ICC). The match rate is intuitive but does not account for chance agreement. Kappa and the match rate across reviewers treat both items and reviewers as fixed but do not account for the ordinal nature of the ratings. The ICC measures the reliability of the expert ratings, treats both items and reviewers as random, and accounts for the ordinal ratings of the cognitive response process ratings. The match rate ranges from 0 (no agreement) to 1 (perfect agreement). Kappa and the ICC account for chance. Kappa ranges from -1 (perfect disagreement) to +1 (perfect agreement), where values around 0 indicate agreement no different from chance alone. The ICC theoretically ranges from 0 (no agreement) to +1 (perfect agreement), although technical issues related to estimating the ICC can result in negative estimated ICC values (Lahey et al. 1983). I look at overall agreement and agreement between individual experts.

I then briefly examine the average question-level ratings across the six experts. I compare this with the ratings from the computerized "expert" questionnaire review system. I also discuss the variation in ratings across the items and across the surveys. Finally, I use Spearman rank-order correlations to look at the relationship between the expert ratings and the item nonresponse rates and percentage of inaccurate reports across the questions. I examine this relationship overall using the average expert ratings and separately for each of the six experts. This allows me to determine whether the questions that were identified as being the most likely to experience problems were also more likely to actually experience data quality failures and the extent to which the experts vary in their ability to discern problematic questions. 
Table I. Reliability of Ratings for Six Expert Reviewers for Two Studies, by Breakdown in the Cognitive Response Process

\begin{tabular}{|c|c|c|c|c|c|c|}
\hline & \multicolumn{3}{|c|}{$\begin{array}{l}\text { WDS } \\
\text { Intraclass }\end{array}$} & \multicolumn{3}{|c|}{$\begin{array}{l}\text { NPSAS } \\
\text { Intraclass }\end{array}$} \\
\hline & Kарра & $\begin{array}{l}\text { Corr. } \\
\text { Coef. }\end{array}$ & $\begin{array}{l}\text { Match } \\
\text { Rate }\end{array}$ & Kappa & $\begin{array}{l}\text { Corr. } \\
\text { Coef. }\end{array}$ & $\begin{array}{c}\text { Match } \\
\text { Rate }\end{array}$ \\
\hline \multicolumn{7}{|l|}{ Motivational } \\
\hline Burden & 0.87 & 0.89 & 0.94 & 0.35 & 0.39 & 0.75 \\
\hline Sensitivity & -0.08 & 0.13 & 0.61 & 0.03 & 0.13 & 0.53 \\
\hline Social Undesirability & 0.28 & 0.33 & 0.80 & 0.35 & 0.40 & 0.83 \\
\hline \multicolumn{7}{|l|}{ Cognitive } \\
\hline Any Failure & 0.28 & 0.36 & 0.64 & 0.32 & 0.37 & 0.66 \\
\hline Comprehension & -0.04 & -0.03 & 0.89 & -0.06 & 0.06 & $0.5 I$ \\
\hline Retrieval & 0.52 & 0.65 & 0.79 & 0.10 & 0.34 & 0.44 \\
\hline Judgment & 1.00 & 1.00 & 1.00 & 0.03 & 0.07 & 0.77 \\
\hline Editing & 0.11 & 0.18 & 0.64 & -0.07 & 0.18 & 0.53 \\
\hline
\end{tabular}

NPSAS = National Postsecondary Student Aid Study; WDS = Wisconsin Divorce Study. All judgment ratings in the WDS were identical, indicating no judgment problems. Motivational factors and "any failure" were coded as $\mathrm{I}=$ Yes, $0=$ No. Cognitive factors were coded on a 4-point scale ranging from $0=$ unlikely failure to $3=$ very likely failure. Intraclass Corr. Coef. is the intraclass correlation coefficient, treating the expert reviewers and questions as random effects. The six experts examined $n=6$ questions in the WDS, for a total of 36 observations and $n=10$ questions in the NPSAS, for a total of 60 observations.

\section{Findings}

\section{Agreement across the Raters}

Substantial disagreement is found in the ratings across expert raters for both studies, regardless of reliability measure (Table 1). This lack of reliability across experts is consistent with other evaluations of consistency across expert reviewers (Presser and Blair 1994; DeMaio and Landreth 2003). Here, this disagreement occurs despite selection of reviewers to be similar in background training. In general, reliability in the NPSAS is substantially lower than that in the WDS. The highest reliability levels are found in the ratings of burden and retrieval for the WDS (kappa = .87). These are also found to be the most reliable ratings in the NPSAS, as is ratings for potential social undesirability. 
To see whether any single reviewer was diminishing the reliability of the estimates, I look at the average match rate for each expert with the other five experts. To do this, I calculate the exact match rate for each expert with each of the other five experts for each survey and then average the five values.

There is no obvious standout in the WDS, with the average match rate across experts ranging from $75 \%$ to $84 \%$. Expert 2 has the lowest rate of agreement with the other reviewers in the NPSAS (an average $44 \%$ match compared to a range of $58-72 \%$ for the other experts). I exclude expert 2 and reestimate all of the NPSAS reliability measures. The largest differences in reliability are found in the "any failure" and "social undesirability" categories. Reliability measures for all of the other categories excluding expert 2 are similar to those including this reviewer. Dropping expert 2 lowers the mean ratings on all categories. Thus, expert 2 identified more problems with the questions than other reviewers. Notably, expert 2 was from the same organization as most of the other reviewers. There is no clear expert that had the highest match rate with the other experts across the two studies.

In other words, the use of experts to identify question problems is itself subject to measurement error. As the raters had no knowledge of the empirical distribution of the measurement errors before conducting the reviews, the ratings are likely to be unbiased, although noisy.

Empirical ratings from expert review. Turning to the ratings themselves, across the six reviewers, cognitive failure breakdowns are rated as likely to occur on $56 \%$ of the questions rated in the WDS and on $48 \%$ of the rated questions in the NPSAS (Table 2). Questions in the NPSAS tend to have higher ratings of cognitive difficulties than those in the WDS, regardless of the domain being examined. Overall, breakdowns at the retrieval stage are rated as the most likely to occur in both surveys. Questions in both studies are rated as having higher likelihoods of editing problems than judgment problems; in particular, no question in the WDS is rated as having any judgment failures. This is not surprising, as the WDS questions are factual autobiographical questions requiring little judgment. In terms of the motivational measures, the experts are more likely to rate these questions as being sensitive or burdensome than socially undesirable. Across the six experts, an average of $42 \%$ of the NPSAS questions are rated as sensitive, compared to $31 \%$ of the questions in the WDS. 


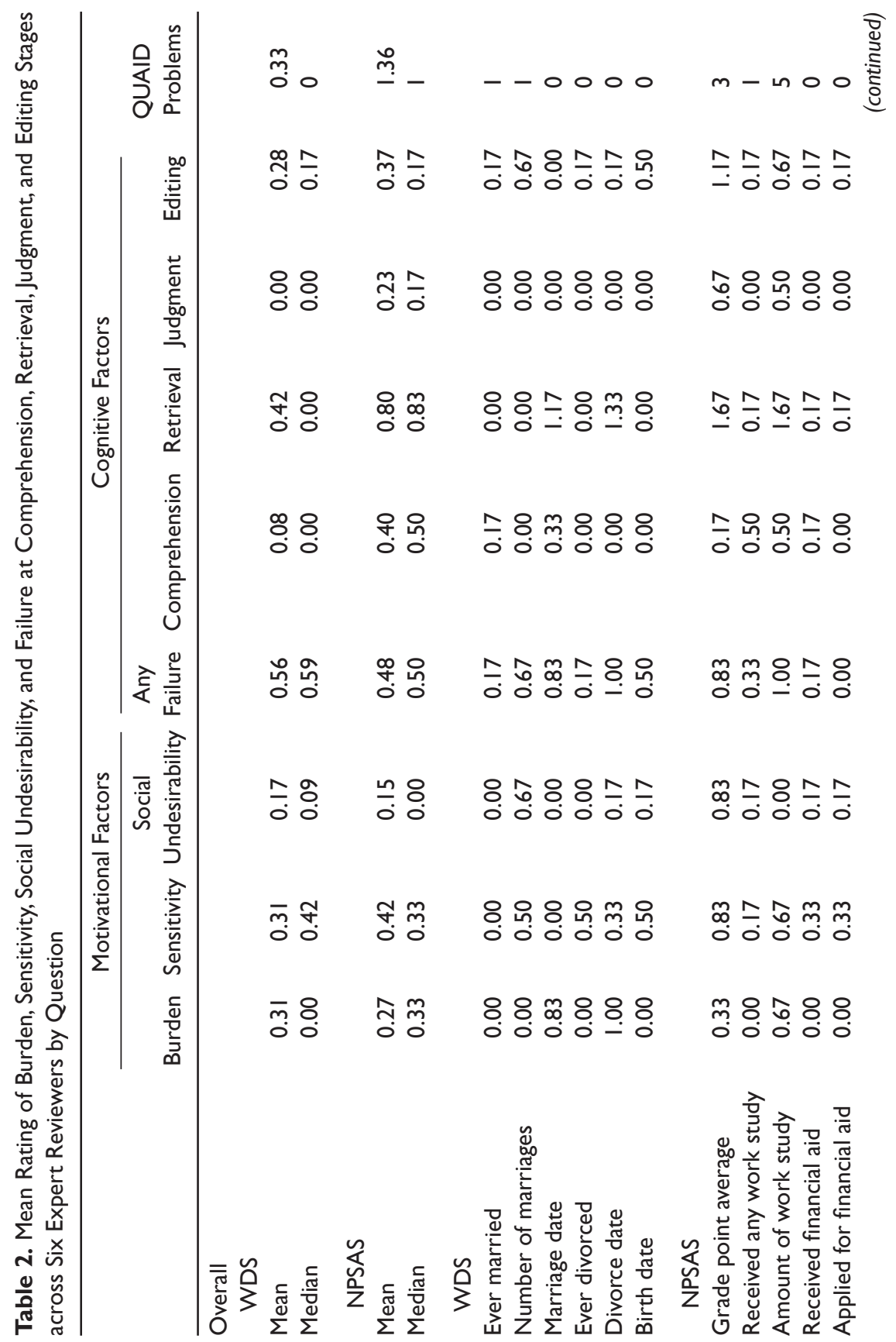




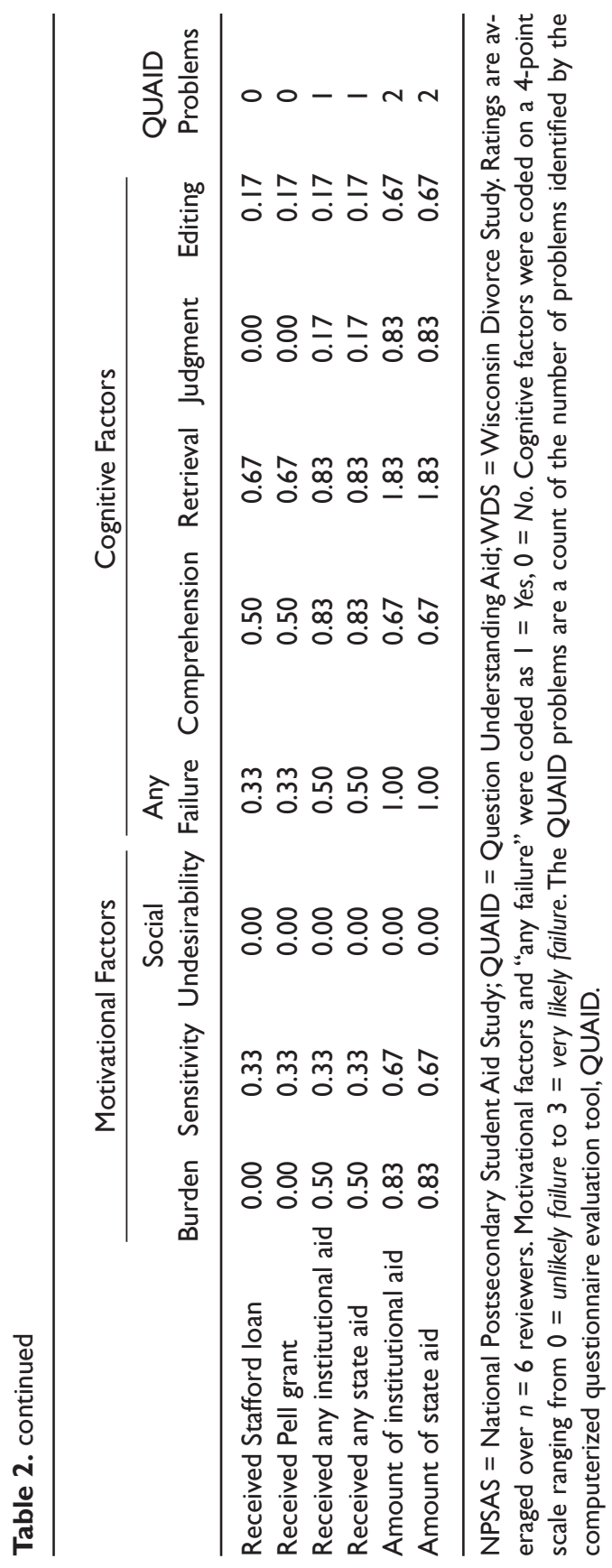


Variation exists in the ratings across questions. Questions related to dates - especially marriage and divorce dates - in the WDS are rated by the experts as being more likely to experience retrieval breakdowns and be burdensome than the other WDS questions. Questions related to the amount of financial aid received in the NPSAS are similarly rated as being more burdensome and having retrieval difficulties. Grade point average is rated as being the most likely to suffer from social desirability concerns and editing problems, the stage of the cognitive response process most closely related to socially desirable responses (Tourangeau et al. 2000).

The computerized expert, QUAID, identified only two questions with minor question wording problems in the WDS. In the NPSAS, seven questions are identified as having some wording problems, with the amount of work study aid earned the most problematic question, followed by grade point average. When looking at the relationship between the QUAID ratings and the expert ratings, I expect the strongest correlations to be with ratings of comprehension problems, given that syntactical problems are related to understanding the question. No significant correlation is found between the QUAID ratings and the expert ratings in the WDS, not surprising given the lack of variation in the QUAID ratings. Surprisingly, however, the QUAID ratings are most strongly related to ratings of editing failures in the NPSAS (Spearman's rho $=.86, p<.001$ ) but not related to comprehension difficulties (Spearman's rho $=.28, p=$ .40). That is, questions identified by the experts as being most likely to pose comprehension difficulties are not similarly identified by the computer tool. This discrepancy between experts and QUAID matches original research on the tool (Graesser et al. 2006). The expert ratings for burden, sensitivity, any failure, retrieval, and judgment are also positively and significantly related $(p<.05)$ to the QUAID ratings.

\section{Relationship between Average Ratings and Data Quality}

The next question is whether the items identified by the experts as being more likely to suffer cognitive or motivational failures are also more likely to have data quality problems (Table 3). When the two studies are combined, positive correlations are found between most of the mean expert ratings and the data quality indicators, indicating that questions rated as being more likely to experience cognitive response or motivational problems are more likely to be questions with higher item nonresponse rates or higher rates of inaccuracy. The size of the Spearman rankorder correlations are low to moderate, ranging from about .05 to .75 in absolute value. Given the small sample sizes (6 questions in the WDS and 
Table 3. Spearman Rank-Order Correlation between Question-Level Expert Ratings, QUAID Rating, and Question-Level Item Nonresponse Rates and Inaccuracy Rates

\begin{tabular}{|c|c|c|c|c|c|c|}
\hline & \multicolumn{2}{|c|}{ Combined } & \multicolumn{2}{|c|}{ WDS } & \multicolumn{2}{|c|}{ NPSAS } \\
\hline & Item & & Item & & Item & \\
\hline & NR & Inaccuracy & NR & Inaccuracy & NR I & Inaccuracy \\
\hline Burden & $0.74 * * *$ & $0.77 * * *$ & $0.85^{*}$ & $0.85 *$ & $0.58+$ & $0.66 *$ \\
\hline Sensitivity & 0.29 & $0.32 * *$ & -0.09 & -0.09 & $0.62 *$ & $0.73 *$ \\
\hline Social undesirability & -0.06 & 0.14 & -0.06 & 0.34 & 0.00 & 0.05 \\
\hline Any failure & $0.7 \mid * * *$ & $0.62 * *$ & 0.70 & $0.93^{* *}$ & $0.78 * *$ & $0.55+$ \\
\hline Comprehension & 0.23 & 0.14 & -0.07 & -0.07 & 0.24 & 0.23 \\
\hline Retrieval & $0.75 * *$ & $0.73 * * *$ & $0.85^{*}$ & $0.85^{*}$ & $0.72 *$ & $0.70 *$ \\
\hline Judgment & $0.44+$ & $0.53 *$ & - & - & $0.74 * *$ & $0.80 * *$ \\
\hline Editing & 0.16 & 0.19 & -0.52 & -0.21 & $0.80 * *$ & $0.64 *$ \\
\hline QUAID Rating & 0.28 & 0.17 & $-0.83 *$ & -0.62 & $0.80 * *$ & $0.52+$ \\
\hline
\end{tabular}

NPSAS = National Postsecondary Student Aid Study; WDS = Wisconsin Divorce Study . - indicates there was no variation in the expert reviews for these questions. $n=6$ WDS questions and $n=10$ NPSAS questions are examined.

$* * * p<.001$

$* * p<.01$

$* p<.05$

$+p<.10$

10 questions in the NPSAS), correlations must have an absolute value above .50 to be statistically significant at the $p<.05$ level overall, above .64 in the NPSAS, and above .83 to be statistically significant in the WDS. The strongest relationship overall is seen between the ratings of retrieval and item nonresponse (rho $=.75, p<.001)$. That is, the questions rated as posing more retrieval problems are also more likely to have higher item nonresponse rates. Overall, ratings of question burden are most strongly indicative of inaccuracy rates across the two surveys.

When the two studies are examined separately, 14 of the 18 associations $(78 \%)$ between the data quality indicators and the expert ratings are statistically significant in the NPSAS, compared to 6 of the $18(33 \%)$ associations in the WDS. This difference between the studies could simply result from more items and more variation in ratings for the NPSAS. In the WDS, with primarily date questions, the only significant positive correlations are between mean ratings of burden and retrieval and item nonresponse (burden rho $=.85, p<.05$, retrieval rho $=.85, p<.05$ ). These categories also have the strongest relationship with inaccurate reports in the 
WDS. In the NPSAS, with primarily financial and academic performance questions, the largest positive Spearman rank-order correlations are with mean ratings of editing (Spearman's rho $=.80, p<.01$, item nonresponse) and judgment (Spearman's rho $=.80, p<.01$, inaccuracy rates). In addition, questions rated by the experts as being more burdensome or sensitive, or posing retrieval problems have higher item nonresponse rates and inaccuracy rates (rho > .5, $p$ at least <.10). This finding is consistent with the prediction that questions identified as problematic by experts have higher levels of measurement error.

In the WDS, questions identified as problematic by QUAID are those with lower item nonresponse rates (rho $=-.83, p<.05$ ), and a negative, but not significant correlation is observed with inaccuracy rates (rho $=$ -.62 , n.s.). This is counter to the hypothesis that the QUAID tool identifies problems with questions that lead to higher levels of measurement error. In contrast to the WDS questions, the ratings from the QUAID tool were significantly associated with item nonresponse and inaccuracy levels on questions in the NPSAS (item nonresponse rho $=.80, p<.01$; inaccuracy rho $=.52, p<.10$ ).

In both surveys, questions rated by the experts as being more likely to have comprehension difficulties have lower item nonresponse rates and lower inaccuracy rates, although the association is not significant in either survey. Given that all of the judgment ratings in the WDS were zero, no correlation can be calculated between judgment and either data quality indicator. In the WDS, the relationship between ratings of editing and the data quality indicators are negative, whereas the relationship is positive in the NPSAS.

\section{Relationship between Individual Expert Ratings and Data Quality}

For the rating categories with low reliability, I expect substantial variation across experts in the relationship between the ratings of problems and the data quality indicators. I expect more consistent associations between the ratings and data quality indicators for rating categories with higher reliability. Figure 1 plots the correlations for each expert's ratings with the question-level inaccuracy rates and item nonresponse rates.

Many observations can be made about Figure 1. First, as expected, within any given rating category, there is variation across experts in the association between the rating and the data quality outcome. The categories that have lower reliability across experts also have greater variation across experts in the association between each expert's ratings and inaccuracy or item nonresponse rates. Second, although there is heterogene- 


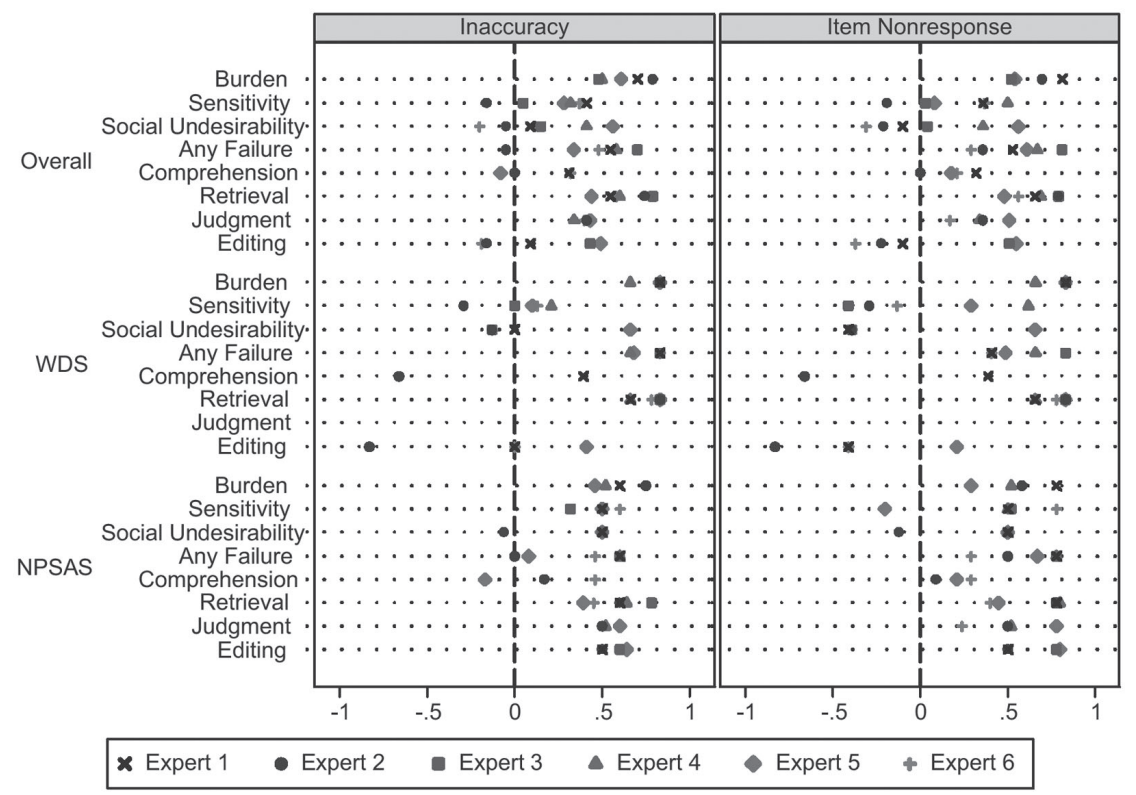

Figure I. Spearman rank-order correlation between question-level expert ratings, QUAID rating, and question-level item nonresponse rates and inaccuracy rates, by expert. Missing points for experts for some ratings indicates there was no variation in the expert's reviews. $n=6$ Wisconsin Divorce Study (WDS) questions and $n=10$ National Postsecondary Student Aid Study (NPSAS) questions are examined here.

ity across experts within a rating category, the more reliable ratings show greater similarity in the association between the expert ratings and the data quality indicators than the less reliable ratings. For example, the correlation between ratings of burden and inaccurate report rates are clustered between .54 and .81 , reflecting the higher reliability $(\mathrm{kappa}=.87)$ across experts in this rating category. In contrast, the correlation between sensitivity ratings (which were highly unreliable, kappa $=-.08$ ) and the inaccurate report rates, varies substantially across reviewers from -0.16 to 0.41 .

Third, the correlation between each expert's ratings and inaccurate reporting rates (the first panel of Figure 1) or item nonresponse rates (the second panel) are largely positive across experts. This indicates that most of the experts are able to discern questions that result in higher or lower data quality through their ratings. Fourth, the correlations are less than one for all experts for all rating categories. Thus, although experts' rat- 
ings discriminate questions that result in better or worse data quality, they are not able to do so perfectly. Given the small number of questions, most of the associations do not meet traditional levels of statistical significance.

Fifth, there is greater consistency across experts in the association between the ratings and data quality problems in the NPSAS than in the WDS. Expert 2 is noticeably different in his or her associations between social undesirability and comprehension problem ratings and data quality in the NPSAS than the rest of the experts. For example, the Spearman rank-order correlation for social undesirability ratings with inaccuracy of reports is -.06 for expert 2 and .50 for four of the remaining five experts (the final expert did not have variation in ratings of this category). As discussed above, social undesirability ratings were those that were the most affected by dropping expert 2 from the overall mean expert ratings.

\section{Discussion}

In this article, I examine whether evaluations of a questionnaire by expert reviewers are consistent across experts and find large inconsistencies. Although the experts here were selected as similar in methodological background and training, both the ratings themselves and the association between the ratings and data quality varied across experts. Unlike some previous research on this topic, this examination does not confound differences in experts with differences in organizations; even with this additional control, variation is found in the problems identified by each expert. This variation across reviewers may be exacerbated if reviewers with more disparate backgrounds are used. This suggests that organizations should ask multiple experts to review a questionnaire in pretests or post-survey evaluations. What characteristics of experts contribute to consistency or discrepancy in ratings needs further research. One potential uncontrolled source of variation is the effort put into the rating task. Although the task itself was standardized across the experts, designed to minimize variation in problem identification, the effort put into the task may not have been identical. Additionally, each expert may have had a different measurement error outcome (e.g., item nonresponse and report inaccuracy) in mind when doing this task. This study did not collect information about the time each expert spent conducting the review, attention to the task, whether the reviewer thought about the risk of a particular type of measurement error, or knowledge of the subject matter of the questionnaires, all factors that may contribute to variation in the quality and reliability of expert reviews. 
Despite the lack of reliability across ratings, the average expert ratings successfully identify questions that are more likely to have higher levels of item nonresponse or inaccurate reporting, although success in this task varies across the surveys and across the six experts. In general, the aggregate ratings best predict item nonresponse and inaccuracy in the NPSAS. This difference across surveys is likely due to small numbers of items to evaluate in the WDS. The computerized QUAID tool does not fare any better than the human experts, and in the WDS, identifies greater numbers of problems with questions that actually yielded better data quality. The QUAID computerized tool identified problems at a fairly discrete level, consistent with many categories used in the Questionnaire Appraisal System, a standardized questionnaire evaluation tool sometimes used by human evaluators (Willis and Lessler 1999). Despite the degree of specificity in the QUAID ratings, the broad ratings by the experts did just as well or better than the specific ratings by QUAID.

Contrary to hypotheses, no relationship was seen between comprehension ratings and the data quality indicators. Many question evaluation methods focus on potential problems with comprehension (Presser and Blair 1994; DeMaio and Landreth 2003). One possible explanation is that the unreliability in the experts' judgment of potential comprehension problems attenuated any potential association with the data quality indicators (Fuller 1987). Alternatively, comprehension problems could manifest in data quality issues only when the mapping between the construct in the questionnaire and the respondent's experience is complicated (Conrad and Schober 2000). It is possible that there were few questions that presented such complicated mappings or that few respondents who experienced problems mapping their retrieved answers to the question. Finally, these questionnaires underwent evaluation and review prior to the start of data collection. It is possible that many comprehension problems were identified during this stage.

The analysis here focused on expert identification of potential problems with factual questions. Because a goal of this article is to examine whether questions identified as potentially posing problems for respondents actually manifest in higher levels of measurement error in respondent reports, this limitation is necessary. Although other items were asked and rated in each survey, these additional questions also were primarily factual given the nature of the surveys. Additional research is needed to examine cross-expert variability in identifying potential problems with attitudinal questions and whether those problems manifest in measurement errors.

Furthermore, when used for pretesting, experts sometimes are asked to suggest changes to question wording in addition to identifying prob- 
lems. Data collection for each survey had been completed at the time of this research, so the experts were asked only to identify problems, not to suggest question wording changes. Although the experts could make more detailed comments on each question in this review, these comments were not consistently made across questions or across experts. As such, whether different experts from the same organization make the same recommendations for changes to question wording is still an open question.

Few studies are able to afford extensive pretests of a survey instrument and rely on experts to identify potential problems. This article indicates that not only do expert reviews identify question problems, but that these problems are related to meaningful data quality issues. Survey practitioners are advised, from this research, to use multiple experts to review questionnaires. Experts are not a uniform group, and this variation should be anticipated when pretesting or reviewing questionnaires. Additionally, questions identified as potentially posing difficult retrieval problems or being burdensome (categories in most evaluation schemes) should receive special attention for potential revision. In particular, these questions, such as those about finances, may pose difficult response tasks that require forms of assistance (e.g., encouraging use of records, bracketed responses, and decomposition) other than question rewording to improve data quality. The experts here were most reliable in identifying these problems; these problems, in turn, were most likely to generate data quality issues such as item nonresponse and inaccurate reports.

\section{Appendix}

\section{Instructions to Experts}

Please code each question for two sets of characteristics. The first set of characteristics has to do with burden, sensitivity, and social desirability. The second set of characteristics has to do with potential failures of the response process.

For each question, rate whether the characteristic measured in the question is

a. Burdensome - requires a great deal of cognitive work by the respondent (yes, no)

b. Sensitive - requires revealing embarrassing or private information or the topic is not discussed in everyday conversation (yes, no)

c. Socially (un)desirable - requires revealing information that may be compared against a social norm for possessing or not possessing a characteristic (yes, no) 
For each question, rate whether a failure of the response process is likely to occur at any stage. If any failure is likely to occur, please rate how likely a failure at each stage in the response process is to occur.

$0=$ Unlikely that a failure of this stage will occur

$1=$ Somewhat likely that a failure of this stage will occur

$2=$ Likely that a failure of this stage will occur

$3=$ Very likely that a failure of this stage will occur

Appendix Table I. Question Wording and Response Options Wisconsin Divorce Study (WDS)

\begin{tabular}{|c|c|c|}
\hline Question & Question Wording & Response Options \\
\hline Ever married & Have you ever been married? & Yes, No \\
\hline $\begin{array}{l}\text { Number of } \\
\text { marriages }\end{array}$ & $\begin{array}{l}\text { How many times have you been } \\
\text { married? }\end{array}$ & Number of times \\
\hline Marriage date & $\begin{array}{l}\text { In what month and year did your } \\
\text { [fill] marriage begin? }\end{array}$ & Month/year \\
\hline Ever divorced & How did this marriage end? & $\begin{array}{l}\text { Separation, Divorce, } \\
\text { Spouse died, Other }\end{array}$ \\
\hline Divorce date & $\begin{array}{l}\text { In what month and year did you } \\
\text { get divorced? }\end{array}$ & Month/year \\
\hline Birth date & What is your date of birth? & Month/year \\
\hline
\end{tabular}

Appendix Table 2. Question Wording and Response Options, NPSAS

\begin{tabular}{|c|c|c|}
\hline Question & Question Wording & Response Options \\
\hline $\begin{array}{c}\text { Grade point } \\
\text { average }\end{array}$ & $\begin{array}{l}\text { What was your cumulative GPA at } \\
\text { [School Name] through the end of } \\
\text { your most recent term in the } \\
2003-2004 \text { school year? }\end{array}$ & $0.00-4.00$ \\
\hline $\begin{array}{l}\text { Received any } \\
\text { work study }\end{array}$ & $\begin{array}{l}\text { During the 2003-2004 school year, } \\
\text { have you participated / did you } \\
\text { participate in either work study } \\
\text { or a paid assistantship? (Please } \\
\text { check all that apply.) } \\
\text { Work-study/ Assistantship }\end{array}$ & Yes, No \\
\hline
\end{tabular}


Appendix Table 2. Question Wording and Response Options, NPSAS (continued)

\begin{tabular}{|c|c|c|}
\hline Question & Question Wording & Response Options \\
\hline $\begin{array}{l}\text { Amount of work } \\
\text { study }\end{array}$ & $\begin{array}{l}\text { How much did you earn from your } \\
\text { [assistantship/work study job] } \\
\text { while you were enrolled during } \\
\text { the 2003-2004 school year? }\end{array}$ & $\begin{array}{l}\text { Amount Per Year, } \\
\text { Term/semester, } \\
\text { Month }\end{array}$ \\
\hline $\begin{array}{l}\text { Received financial } \\
\text { aid }\end{array}$ & $\begin{array}{l}\text { Besides your [work study/assistant- } \\
\text { ship] did you receive any other } \\
\text { financial aid —such as grants, } \\
\text { loans, or scholarships during the } \\
2003-2004 \text { school year?/ Did } \\
\text { you receive financial aid_- such } \\
\text { as grants, loans, or scholarships } \\
\text { during the 2003-2004 school year? }\end{array}$ & Yes, No \\
\hline $\begin{array}{l}\text { Applied for } \\
\text { financial aid }\end{array}$ & $\begin{array}{l}\text { Did you apply for financial aid } \\
\text { for the 2003-2004 school year? }\end{array}$ & Yes, No \\
\hline $\begin{array}{l}\text { Received } \\
\text { Stafford loan }\end{array}$ & $\begin{array}{l}\text { Did you receive a federal Stafford } \\
\text { student loan for the 2003-2004 } \\
\text { school year? }\end{array}$ & Yes, No \\
\hline $\begin{array}{l}\text { Received Pell } \\
\text { Grant }\end{array}$ & $\begin{array}{l}\text { Did you receive a Pell grant for } \\
\text { the } 2003-2004 \text { school year? }\end{array}$ & Yes, No \\
\hline $\begin{array}{l}\text { Received state } \\
\text { aid/Received } \\
\text { institutional aid }\end{array}$ & $\begin{array}{l}\text { Did you receive any scholarships or } \\
\text { grants from your school or from a } \\
\text { state grant program during the } \\
\text { 2003-2004 school year? State } \\
\text { grant or scholarship, School } \\
\text { grant/scholarship, Did not receive } \\
\text { state or college aid }\end{array}$ & Yes, No \\
\hline $\begin{array}{l}\text { Amount of state } \\
\text { aid/Amount of } \\
\text { institutional aid }\end{array}$ & $\begin{array}{l}\text { Did you receive any scholarships or } \\
\text { grants from your school or from } \\
\text { a state grant program during the } \\
2003-2004 \text { school year? State } \\
\text { grant/scholarship amount, } \\
\text { school grant/scholarship amount }\end{array}$ & Amount \\
\hline
\end{tabular}

Brackets ([ ]) indicate a fill in the computer-assisted interview or Web survey. 


\section{Acknowledgments}

The material for this article is based on work supported by a National Science Foundation grant (SES-0620228). The Wisconsin Divorce Study was funded by a grant (HD- 31035 \& HD32180-03) from the National Institute of Child Health and Human Development, National Institutes of Health (PIs: Vaughn Call and Larry Bumpass). The author would like to thank the experts who contributed their time and effort to this study and NCES and RTI international for providing access to the NPSAS. The author would also like to thank Bob Groves and Norman Bradburn for feedback on the study design and Rachel Levenstein, Bob Belli, and three anonymous reviewers for comments on earlier drafts.

\section{References}

American Association for Public Opinion Research. 2006. Standard definitions: Final dispositions of case codes and outcome rates for surveys (4th ed.). Lenexa, KS: The American Association for Public Opinion Research.

Banerjee, M., M. Capozzoli, L. McSweeney, and D. Sinha. 1999. Beyond kappa: A review of interrater agreement measures. The Canadian Journal of Statistics 27:3-23.

Cannell, C. F., P. V. Miller, and L. Oksenberg. 1981. Research on interviewing techniques. Sociological Methodology 12:389-437.

Cominole, M., P. Siegel, K. Dudley, D. Roe, T. Gilligan, and J. Griffith. 2006. 2004 National Postsecondary Student Aid Study (NPSAS:04) full scale methodology report. Washington, DC: U.S. Department of Education, National Center for Education Statistics.

Conrad, F. G., and M. F. Schober. 2000. Clarifying question meaning in a household telephone survey. Public Opinion Quarterly 64:1-28.

DeMaio, T. J., and A. Landreth. 2003. Examining expert reviews as a pretest method. In ZUMA-Nachrichten Spezial Band 9, questionnaire evaluation standards, ed. P. Prüfer, M. Rexroth, J. Fowler, and F. Jackson, 60-73. Mannheim, Germany: ZUMA.

Esposito, J. L., and J. Rothgeb. 1997. Evaluating survey data: Making the transition from pretesting to quality assessment. In Survey measurement and process quality, ed. L. Lyberg, P. Biemer, M. Collins, E. De Leeuw, C. Dippo, N. Schwarz, and D. Trewin, 541-71. New York: John Wiley and Sons.

Forsyth, B., J. M. Rothgeb, and G. B. Willis. 2004. Does pretesting make a difference? An experimental test. In Methods for testing and evaluating survey questionnaires, ed. S. Presser, J. M. Rothgeb, M. P. Couper, J. T. Lessler, E. Martin, J. Martin, and E. Singer, 525-46. New York: John Wiley and Sons.

Fuller, W. 1987. Measurement error models. New York: John Wiley and Sons.

Graesser, A. C., Z. Cai, M. M. Louwerse, and F. Daniel. 2006. Question Under- 
standing Aid (QUAID): A web facility that helps survey methodologists improve the comprehensibility of questions. Public Opinion Quarterly 70:1-20.

Holbrook, A. L., J. A. Krosnick, D. Moore, and R. Tourangeau. 2007. Response order effects in dichotomous categorical questions presented orally: The impact of question and respondent attributes. Public Opinion Quarterly 71:325-48.

Jansen, H., and T. Hak. 2005. The productivity of the Three-Step Test-Interview (TSTI) compared to an expert review of a self-administered questionnaire on alcohol consumption. Journal of Official Statistics 21:103-20.

Kalton, G., and R. Stowell. 1979. A study of coder variability. Applied Statistics 28:276-89.

Lahey, M. A., R. G. Downey, and F. E. Saal. 1983. Intraclass correlations: There's more there than meets the eye. Psychological Bulletin 93:586-95.

Mangione, T. W., F. J. Fowler Jr., and T. A. Louis. 1992. Question characteristics and interviewer effects. Journal of Official Statistics 8:293-307.

Presser, S., and J. Blair. 1994. Survey pretesting: Do different methods produce different results? Sociological Methodology 24:73-104).

Ramirez, C. 2002. Strategies for subject matter expert review in questionnaire design. Paper presented at the Questionnaire Design, Evaluation, and Testing Conference, Charleston, SC. http://www.jpsm.umd.edu/qdet/final_pdf_papers/ramirez.pdf (accessed February 18, 2006).

Rothgeb, J., G. Willis, and B. Forsyth. 2001. Questionnaire pretesting methods: Do different techniques and different organizations produce similar results? Paper presented at the annual meeting of the American Association for Public Opinion Research, Montreal, Canada. Proceedings of survey research methods section of the American Statistical Association. Washington, DC: American Statistical Association.

Schaeffer, N. C., and J. Dykema. 2004. A multiple-method approach to improving the clarity of closely related concepts: Distinguishing legal and physical custody of children. In Methods for testing and evaluating survey questionnaires, ed. S. Presser, J. M. Rothgeb, M. P. Couper, J. T. Lessler, E. Martin, J. Martin, and E. Singer, 475-502. New York: John Wiley and Sons.

Schnell, R., and F. Kreuter. 2005. Separating interviewer and sampling-point effects. Journal of Official Statistics 21:389-410.

Schrout, P. E., and J. L. Fleiss. 1979. Intraclass correlations: Uses in assessing rater reliability. Psychological Bulletin 86:420-28.

Theis, B., J. Frood, D. Nishri, and L. D. Marrett. 2002. Evaluation of a risk factor survey with three assessment methods. Chronic Diseases in Canada 23:1-12.

Tourangeau, R. 1984. Cognitive sciences and survey methods. In Cognitive aspects of survey methodology: Building a bridge between disciplines, ed. T. B. Jabine, M. L. Straf, J. M. Tanur, and R. Tourangeau, 73-100. Washington, DC: National Academies Press. 
Tourangeau, R. 2004. Experimental design considerations for testing and evaluating questionnaires. In Methods for testing and evaluating survey questionnaires, ed. S. Presser, J. M. Rothgeb, M. P. Couper, J. T. Lessler, E. Martin, J. Martin, and E. Singer, 209-24. New York: John Wiley and Sons.

Tourangeau, R., L. J. Rips, and K. A. Rasinski. 2000. The psychology of survey response. Cambridge: Cambridge University Press.

Willis, G., and J. T. Lessler. 1999. Question Appraisal System QAS-99. Rockville, MD: Research Triangle Institute.

Willis, G. B., S. Schechter, and K. Whitaker. 1999. A comparison of cognitive interviewing, expert review, and behavior coding: What do they tell us? Paper presented at the Joint Statistical Meetings, Baltimore, MD. Proceedings of Survey Research Methods Section of the American Statistical Association (28-37). Washington, DC: American Statistical Association. 